\title{
Review
}

\section{Genetic evidence in the mouse solidifies the calcium hypothesis of myofiber death in muscular dystrophy}

\author{
AR Burr ${ }^{1}$ and JD Molkentin ${ }^{\star, 1,2}$
}

Muscular dystrophy (MD) refers to a clinically and genetically heterogeneous group of degenerative muscle disorders characterized by progressive muscle wasting and often premature death. Although the primary defect underlying most forms of MD typically results from a loss of sarcolemmal integrity, the secondary molecular mechanisms leading to muscle degeneration and myofiber necrosis is debated. One hypothesis suggests that elevated or dysregulated cytosolic calcium is the common transducing event, resulting in myofiber necrosis in MD. Previous measurements of resting calcium levels in myofibers from dystrophic animal models or humans produced equivocal results. However, recent studies in genetically altered mouse models have largely solidified the calcium hypothesis of MD, such that models with artificially elevated calcium in skeletal muscle manifest fulminant dystrophic-like disease, whereas models with enhanced calcium clearance or inhibited calcium influx are resistant to myofiber death and MD. Here, we will review the field and the recent cadre of data from genetically altered mouse models, which we propose have collectively mostly proven the hypothesis that calcium is the primary effector of myofiber necrosis in MD. This new consensus on calcium should guide future selection of drugs to be evaluated in clinical trials as well as gene therapy-based approaches.

Cell Death and Differentiation (2015) 22, 1402-1412; doi:10.1038/cdd.2015.65; published online 19 June 2015

Facts

- The primary myofiber death-inducing effect underlying muscular dystrophy (MD) is an unstable plasma membrane and an associated dysregulation in calcium handling or influx.

- Genetic data in mice shows that unregulated cellular calcium entry alone is sufficient to induce myofiber death and MD.

- Genetic data in mice shows that enhanced calcium clearance from the cytosol mitigates myofiber death and MD.

- Genetic data in mice shows that making mitochondria insensitive to calcium overload reduces myofiber death and MD.

\section{Open Questions}

- Is the calcium overload or dysregulation that occurs in MD primarily due to membrane ruptures or dysregulated ion channel and exchanger activity?

- What intracellular domains of calcium dysregulation most directly couple to initiation of myofiber death in MD?
- Given our recent consensus on calcium as the common mediator of myofiber death in MD, what calcium-affecting drugs might be best to attempt for use in human clinical trials?

MD is a disease of progressive muscle weakness and degeneration of myofibers caused by mutations in genes that often serve a structural role in stabilizing the plasma membrane of the myofibers (referred to as the sarcolemma). Duchenne MD (DMD) is an X-linked recessive genetic disease that is the most common form of $M D$ in humans with an occurrence of $\sim 1$ in 3500 males. ${ }^{1}$ Dystrophin, the protein encoded by the gene mutated in DMD, functions in stabilizing the sarcolemma, as do a host of other gene products that when mutated result in limb-girdle MDs, congenital MDs, and various myopathies. ${ }^{2}$ Loss of select sarcolemmal structural gene products or even gene products involved in membrane repair, such as dysferlin, lead to membrane instability and a hypothesized influx of calcium that serves as the final common pathway leading to myofiber necrosis and muscle degeneration. ${ }^{3}$ However, this model of pathogenesis with calcium serving as the central transducer of myofiber death

\footnotetext{
${ }_{1}^{1}$ Department of Pediatrics, Cincinnati Children's Hospital Medical Center, University of Cincinnati, Cincinnati, 240 Albert Sabin Way, Cincinnati, OH, USA and ${ }^{2}$ Department of Pediatrics, Cincinnati Children's Hospital Medical Center, Howard Hughes Medical Institute, Molecular Cardiovascular Biology, 240 Albert Sabin Way, Cincinnati, OH, USA

${ }^{*}$ Corresponding author: JD Molkentin, Department of Pediatrics, Cincinnati Children's Hospital Medical Center, Howard Hughes Medical Institute, Molecular Cardiovascular Biology, 240 Albert Sabin Way, MLC 7020, Cincinnati 45229, OH, USA. Tel: +1 513636 3557; Fax +1 513 6365958; E-mail: jeff.molkentin@ cchmc.org Abbreviations: CK, creatine kinase; CypD, cyclophilin D; DMD, Duchenne muscular dystrophy; dn, dominant negative; IP ${ }_{3} R$, inositol 1,4,5-triphosphate receptor; MD, muscular dystrophy; MPTP, mitochondrial permeability transition pore; NADPH, nicotinamide adenine dinucleotide phosphate; NCX, sodium-calcium exchanger; NHE, sodium-hydrogen exchanger; NKA, sodium-potassium ATPase; ROCE, receptor-operated calcium entry; RyR, ryanodine receptor; SR, sarcoplasmic reticulum; SERCA, sarcoplasmic/endoplasmic reticulum calcium ATPase; TRPC, transient receptor potential canonical; TRPV, transient receptor potential vanilloid; X-ROS, X-reactive oxygen species

Received 01.12.14; revised 03.4.15; accepted 17.4.15; Edited by L Scorrano; published online 19.6.15
} 
has remained a hypothesis, and although many biochemical lines of evidence support this hypothesis, it was not until the past few years that the use of mouse genetics allowed for a more definitive analysis of this 'calcium hypothesis'.

The concept that membrane instability could lead to calcium overload, mitochondrial dysfunction, and ultimately the necrosis of myofibers predates the discovery of dystrophin. This calcium hypothesis was originally proposed as a final common pathway for multiple neuromuscular diseases in 1976 by Wrogemann, which remains remarkably accurate and an impressive deduction given the limited data available at the time. ${ }^{4}$ Here, we will review the body of evidence that we believe has solidified the concept that calcium serves as the common intracellular transducer of myofiber necrosis in most forms of MD, with a special emphasis placed on data derived from recent genetic studies in the mouse.

\section{Excitation Contraction-Coupling}

The process of muscle contraction is initiated by acetylcholine binding to the acetylcholine receptor in motor neurons at the end plates, leading to the opening of voltage-gated sodium channels across the sarcolemma and down the t-tubules into the myofibers. The wave of depolarization leads to a conformational change in the L-type calcium channel and a direct gating of the ryanodine receptor (RyR) within the sarcoplasmic reticulum (SR), allowing for a very large release of calcium causing muscle contraction. Muscle relaxation occurs as the SR calcium-ATPase (SERCA) pumps calcium from the cytoplasm back into the SR (Figure 1).

Alterations in excitation contraction-coupling have been observed in MD. Indeed, muscle weakness is a hallmark of DMD, with a slowing in relaxation that suggests a defect in SRcalcium reuptake. 5,6 Interestingly, although the mothers of boys with DMD that only contain one functional dystrophin gene do not typically show muscle weakness, their muscles do relax slower than normal controls. ${ }^{7}$ These early studies of muscle physiology in boys with DMD and their mothers provided the first evidence that there may be a deficit in calcium handling in muscular dystrophies, but it was not until the discovery of the $m d x$ mouse that calcium handling could be more thoroughly dissected.

Like boys with DMD, the $m d x$ mouse model of MD has a loss-of-function mutation in dystrophin. Although the $\mathrm{mdx}$ mouse only has a modest $10-20 \%$ deficit in specific force generation in the hindlimb musculature, it has a much more severe deficit in relaxation that is suggestive of a major problem in calcium reuptake by the SR. ${ }^{8-10}$ Thus, a deficit in relaxation appears to be an evolutionarily conserved aspect of MD that is prominent even in the mildly pathologic $m d x$ mouse. ${ }^{11,12}$ Such a defect in relaxation is predicted to result in prolonged elevations in cytosolic calcium under continuous contractile activity.

Initial studies with fluorescent calcium-indicator dyes reported that excitation contraction-coupling was unchanged in myofibers from $m d x$ mice compared with wild-type controls. ${ }^{13}$ However, subsequent studies consistently observed

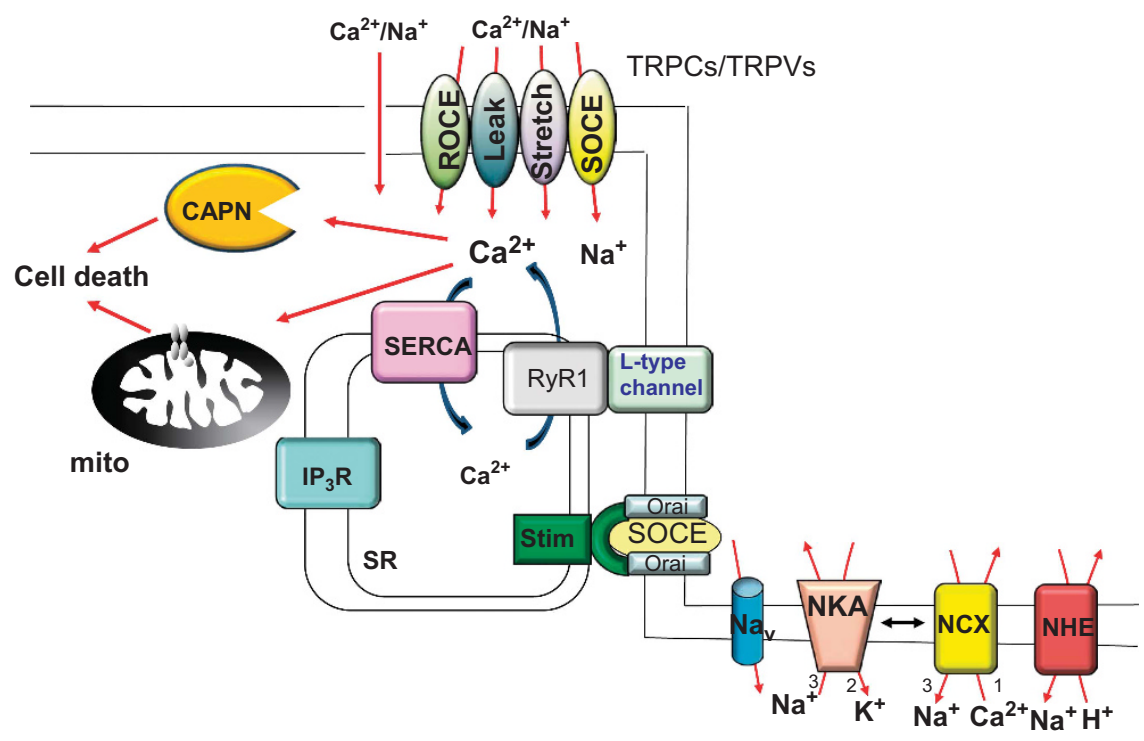

Figure 1 Schematic of the calcium handling proteins and downstream calcium-regulated effectors that are involved in calcium dysregulation in MD, leading to myofiber necrosis. Elevations in resting calcium has been associated with increased store-operated calcium entry (SOCE), increased stretch-activated calcium entry, increased calcium leak, and increased receptor-operated calcium entry (ROCE), attributed to the activity of transient receptor potential canonical (TRPC) and vanilloid (TRPV) family members, as well as by Stim and Orai family member proteins that can directly generate a store-operated calcium entry event. The L-type calcium channel might also be responsible for some content of pathologic calcium influx, as well as leak from the RyR1 in dystrophic skeletal muscle. In addition to elevations in calcium, sodium is increased in the cytosol of dystrophic myofibers owing to increased activity of TRPC channels, sodium channels $\left(\mathrm{Na}_{\mathrm{v}}\right)$, or possibly in conjunction with less effective sodium extrusion by the sodium-potassium ATPase (NKA) pump. Elevated intracellular sodium can secondarily increase resting calcium levels by causing reverse-mode calcium influx through the sodium-calcium exchanger (NCX) as well as by altering NHE1 activity. Sarcoplasmic reticulum (SR) calcium reuptake is also reduced in MD with decreased function of the SERCA pump. Finally, pathologic calcium may also arise owing to increased $I_{3} R$ activity. In response to this pathologic profile of elevated intracellular calcium, the mitochondria (mito) can swell and rupture owing to MPTP activation, and intracellular proteins can be degraded by the calpains (CAPN) 
that the decay phase of the calcium transient was prolonged in $m d x$ muscle fibers, consistent with the profile of delayed relaxation observed in intact muscle. ${ }^{14,15}$ The mechanism of slowed reuptake appears to be due to decreased SERCA activity, which has been observed in microsomes from boys with DMD, $\mathrm{Sgcd}^{-1}$ mice (mouse model of limb-girdle MD due to loss of $\delta$-sarcoglycan gene, which similarly disrupts the dystrophin-glycoprotein complex similar to that observed in $m d x$ mice with the loss of dystrophin) and $d y^{2 j} / d y^{2 j}$ mice that have a mutation in Lama2. ${ }^{15-17}$ The slowed reuptake across a diversity of dystrophic models suggests that decreased SERCA function may be a generalizable feature of many of the muscular dystrophies.

More recent studies utilizing low-affinity calcium-indicator dyes that more faithfully measure the calcium transient, along with computer modeling to estimate calcium release, have found that calcium release is slower in $m d x$ fibers. ${ }^{18}$ In addition to deficits in the velocity of calcium release, the localization of calcium release is also changed in $m d x$ muscle fibers in a more diffuse pattern. ${ }^{19}$ This is interesting because dystrophin localizes to the sarcolemma junction with the SR at the triads, and thus may have a role in patterning calcium release. ${ }^{20}$ Deficits in the patterning of calcium release are likely to expose greater subcellular regions of the muscle fiber to higher concentrations of calcium than would otherwise occur. This situation could expose mitochondria to higher calcium levels, and if sustained, could lead to mitochondrial swelling, rupture, and necrosis of the muscle fiber (this issue will be discussed in greater detail later).

\section{Resting intracellular Calcium Concentration}

Although muscle utilizes calcium in a highly specialized manner to regulate contraction and relaxation, multiple other calcium-sensitive intracellular regulatory processes still proceed and must be adequately regulated. One of these processes is opening of the mitochondrial permeability transition pore (MPTP) in response to calcium overload, which causes mitochondrial depolarization and eventual swelling and rupture of this organelle. ${ }^{21,22}$ Calcium overload also promotes activation of the calcium-activated protease calpain, which has also been shown to contribute to the pathogenesis of MD. ${ }^{23,24}$ These calcium-regulated degenerative processes are likely governed both by the amplitude and duration of calcium present in the cytosol, likely during contraction and at rest. Initial attempts to quantify resting intracellular calcium in dystrophin-deficient myofibers utilized biopsy specimens from boys with DMD. ${ }^{25-27}$ Three techniques available at the time were X-ray fluorescence, histochemical staining, and atomic absorption spectrophotometry, all of which showed higher resting calcium in muscle from boys with DMD. ${ }^{25-27}$ However, later studies conducted with the newly available fluorescent calcium-indicator dyes such as Fura-2 and Indo-1 produced equivocal results that partially 'unseated' the calcium hypothesis (Table 1). ${ }^{13,28-30}$ Although it is possible that resting calcium is truly elevated as identified in later studies with arguably more definitive technical approaches (see below), it is also possible that the key biologic effect underlying myofiber degeneration is due to defects in total calcium dynamics,

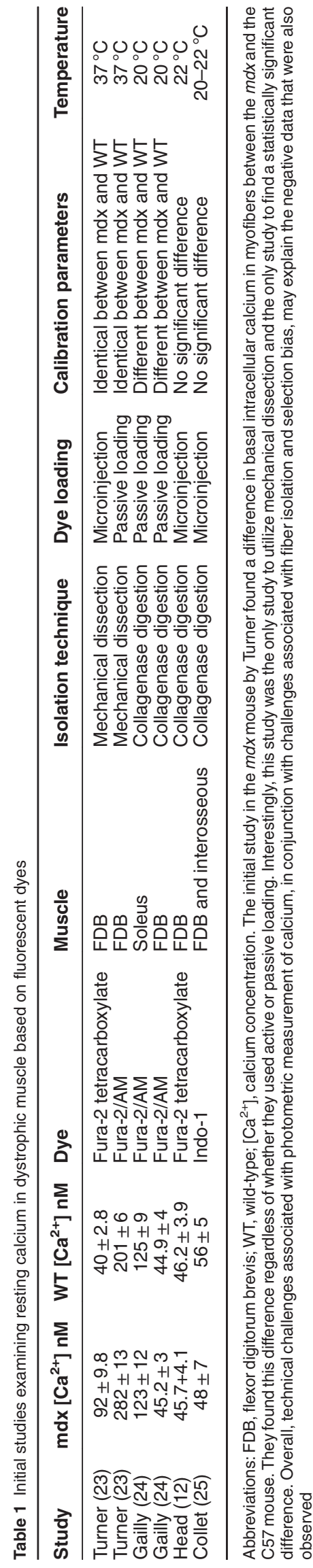


such as rates of calcium release and reuptake, as well as subcellular domain-specific calcium elevations.

The recent use of calcium-sensitive microelectrodes has supported the hypothesis of increased resting calcium in dystrophic myofibers, although this method of measurement is not without some limitations. ${ }^{31-33}$ For example, Altamirano et $a .^{34}$ used calcium microelectrodes to show that resting intracellular calcium was increased to $308 \mathrm{nM} \pm 6 \mathrm{nM}$ in $m d x$ myotubes compared with $113 \mathrm{nM} \pm 2 \mathrm{nM}$ in wild-type myotubes, and in vivo resting calcium was measured to be 315 $\mathrm{nM} \pm 8 \mathrm{nM}$ in $m d x$ gastrocnemius versus $112 \mathrm{nM} \pm 2 \mathrm{nM}$ in wild-type gastrocnemius. ${ }^{32}$ We also observed a threefold elevation in intracellular resting calcium in the gastrocnemius muscle from $m d x$ mice using microelectrode technology. ${ }^{33}$ The caveats with using microelectrode technology are twofold. First, given the known weakness of the dystrophic membrane, a leak around the microelectrode may cause a spurious increase in the intracellular calcium that is recorded. Second, puncture of the muscle cell membrane is a form of cellular injury that could also alter calcium measurements. However, measurements of resting calcium in wild-type fibers with the microelectrode approach matches those values obtained with calcium-sensitive fluorescent dyes.

Another hypothesis is that selective calcium microdomains might be altered in dystrophic myofibers leading to disease. In 2001, Robert et al. used calcium sensing aequorin protein targeted to different intracellular locations. They showed that a subsarcolemmal aequorin protein detected increased calcium levels in $m d x$ myotubes. ${ }^{35}$ Mallouk et al. ${ }^{36}$ used a calciumactivated potassium channel to detect increased subsarcolemmal calcium concentrations in $m d x$ mice. A membrane localized calcium-sensitive dye, FFP-18, also showed significantly elevated levels of subsarcolemmal calcium in myofibers from $m d x$ mice. ${ }^{37}$ The concept of microdomains of calcium is well-known in cardiovascular biology but further work is still required to understand its role in the pathogenesis of $\mathrm{MD}$ and the potential for therapeutic applications. ${ }^{38}$

\section{Role of the L-type Calcium Channel}

As discussed earlier, the L-type calcium channel (a1s subunit encodes the channel itself) is largely mechanically coupled to the RyR in skeletal muscle, without a requirement for external calcium to pass through the channel. Given this feature it would appear to be a relatively poor target for pharmacologic antagonism in possibly treating DMD in humans. Indeed, clinical trials undertaken with L-type calcium channel inhibitors including diltiazem, verapamil, nifedipine and flunarizine have produced mixed results (Figure 2). ${ }^{39-43}$ The study with verapamil reported a significant improvement in muscle strength but unfortunately this was also accompanied by cardiac side effects. ${ }^{43} \mathrm{~A}$ trial with diltiazem showed decreased deterioration of muscle from biopsies of the lower but not upper extremities, suggesting that under certain conditions there may be a small positive effect of these inhibitors. ${ }^{44}$ These mixed results are nonetheless encouraging given that even a theoretically poor target in the calcium handling pathway of skeletal muscle produced some clinical effect when inhibited.

L-type calcium channel inhibitors have also been used in animal models of MD. In one study $m d x$ mice were injected with saline, diltiazem, or verapamil for 18 days. The mice given either of the two calcium channel inhibitors showed decreased levels of circulating creatine kinase and decreased necrosis in the diaphragm. ${ }^{45} \mathrm{~A}$ more recent study observed that after 1 week of treatment of $m d x$ mice with nifedipine, intracellular calcium was decreased and grip strength and swimming times were increased. ${ }^{32}$ Overall, these studies in mice and humans suggest that the small amount of calcium influx from the L-type channel may contribute to the pathogenesis of MD. L-type

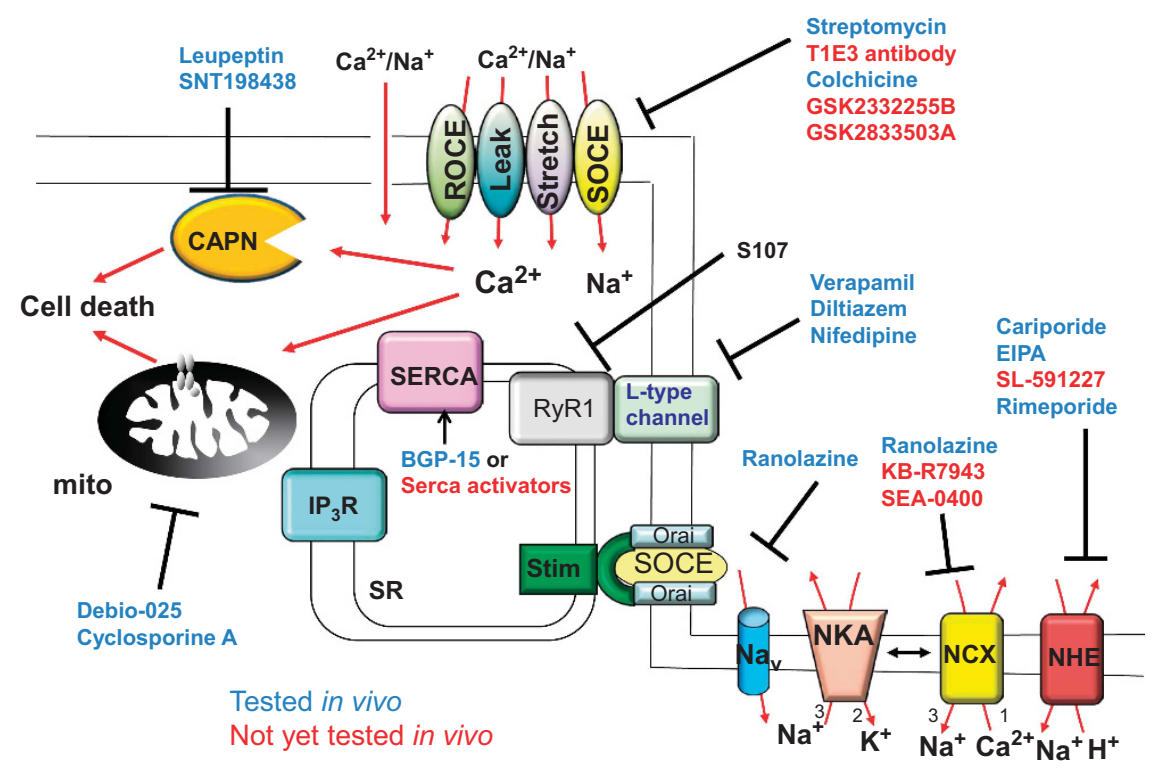

Figure 2 Schematic of the pharmacologic agents that have been or could be used to address a profile of elevated calcium in dystrophic muscle. Drugs previously tested in dystrophic mouse models are shown in blue text, whereas those that are more experimental are shown in red text 
calcium channel inhibitors are interesting targets because of the fact that they are already clinically approved for human use (Figure 2).

\section{SR Calcium Regulation in MD}

As discussed earlier, myofibers from dystrophic mice or DMD patients show a defect in SR-calcium handling and reuptake during relaxation. ${ }^{11-17,46}$ Indeed, we showed that myofibers from $\mathrm{Sgcd}^{-1}$ and $\mathrm{mdx}$ mice have significantly slower reuptake of calcium and that this defect can be corrected by overexpression of SERCA1 through transgenesis, leading to a marked lessening of myofiber necrosis and muscle wasting (Table 2). ${ }^{15}$ Furthermore, adeno-associated virus delivery of SERCA2 rescued pathology in the hindlimb of $\mathrm{Sgcd}^{-1}$ mice, and in a separate study, viral delivery of SERCA1a was shown to decrease pathology in the diaphragm of dystrophic mice. ${ }^{15,47}$ Because the SERCA2 vector utilized is already in clinical trials for congestive heart failure, ${ }^{48}$ viral delivery of SERCA2 could be a clinical option in the future (Figure 2). Overall, the data obtained by SERCA overexpression are highly supportive of the calcium hypothesis of disease in MD, as they suggest that increasing the rate of calcium clearance during relaxation reduces myofiber necrosis. Indeed, the drug
BGP-15 increased SERCA activity and reduced muscle pathology in $m d x$ mice, resulting in greater muscle-specific force. ${ }^{49}$ Thus, in addition to gene therapy, the use of pharmacologic agents that increase SERCA expression or activity is also an interesting strategy to consider in the future.

Modification of calcium release from the SR has also been investigated through genetic strategies. For example, calcium sparks can be readily observed in myofibers from dystrophic muscle, although they are typically never observed in wild-type myofibers. ${ }^{50}$ Sparks are attributed to unregulated opening of a group of RyRs, suggesting that in dystrophic muscle the RyR channels might be leaking calcium. ${ }^{50,51}$ Mechanistically, calcium sparks are normally inhibited by the protein calstabin. In $m d x$ muscle fibers, calstabin binds less avidly to the RyR leading to leak, ${ }^{52,53}$ and restoring this interaction with the drug $\mathrm{S} 107$ (Figure 2) ${ }^{53}$ decreased MD disease in $\mathrm{mdx}$ and $\mathrm{Sgcb}^{-/-}$ mice. ${ }^{54,55}$ Thus, just as correction in calcium leak from the SR was sufficient to partially rescue dystrophic pathology, similar to how overexpression of SERCA might also be protective by better maintenance of resting calcium.

Although less studied than the RyR complex, calcium release from the $S R$ via the inositol $(1,4,5)$-triphosphate receptor $\left(\mathrm{IP}_{3} \mathrm{R}\right)$ may also have an important role in the

Table 2 Summary of findings of genetic manipulations of calcium handling in transgenic used to investigate mechanisms of MD pathology

\begin{tabular}{|c|c|c|c|c|}
\hline Genetic alteration & Year & Dystrophy model & Change in calcium handling & Change in phenotype \\
\hline \multicolumn{5}{|l|}{ Sarcolemma } \\
\hline dn TRPC6 transgenic ${ }^{81}$ & 2009 & $m d x$ and $\mathrm{Sgcd}^{-}$ & $\begin{array}{l}\text { dnTRPC6 inhibited increased SOCE in } \\
\mathrm{Sgcd}^{-1-} \text { fibers }\end{array}$ & $\begin{array}{l}\text { dnTRPC6 TG reduced histopathology } \\
\text { and serum CK }\end{array}$ \\
\hline Trpc3 overexpression ${ }^{81}$ & 2009 & Trpc3 transgenic & Increased SOCE versus WT & $\begin{array}{l}\text { TRPC3 TG caused dystrophy-like } \\
\text { histopathology without membrane } \\
\text { permeability }\end{array}$ \\
\hline Adenoviral dnTRPV2 ${ }^{88}$ & 2008 & Bio14.6 hamster & $\begin{array}{l}\text { Decreased calcium influx in high-calcium } \\
\text { solution }\end{array}$ & $\begin{array}{l}\text { dnTRVP2 decreased dystrophic } \\
\text { histopathology }\end{array}$ \\
\hline Transgenic dnTRPV2 ${ }^{88}$ & 2008 & $m d x$ & $\begin{array}{l}\text { Decreased calcium influx in high-calcium } \\
\text { with } 2 \text {-APB }\end{array}$ & $\begin{array}{l}\text { dnTPV2 improved muscle function and } \\
\text { decreased histopathology }\end{array}$ \\
\hline Trpv2 $-1-89$ & 2009 & $m d x$ & Not evaluated & $\begin{array}{l}\text { Trpv } 2^{-/} \text {had increased force and } \\
\text { decreased membrane permeability }\end{array}$ \\
\hline Stim1 transgenic ${ }^{87}$ & 2014 & Stim1 transgenic & $\begin{array}{l}\text { Stim1 overexpression increased SOCE } \\
\text { and resting calcium }\end{array}$ & $\begin{array}{l}\text { Stim1 TG led to severe dystrophy-like } \\
\text { phenotype in muscle }\end{array}$ \\
\hline dnOrai1 $\operatorname{Tg}^{87}$ & 2014 & $m d x$ and $\mathrm{Sgcd}^{-}$ & $\begin{array}{l}\text { dnOrai inhibited increased SOCE in } \\
\mathrm{SgCd}^{-1-} \text { and } \mathrm{mdx} \text { fibers }\end{array}$ & $\begin{array}{l}\text { dnOrai TG decreased histopathology and } \\
\text { CK release in muscle }\end{array}$ \\
\hline$N C \times 1 T^{33}$ & 2014 & $\begin{array}{l}\text { mdx, } \text { Sgcd }^{--} \\
\text {and Dysf }\end{array}$ & $\begin{array}{l}\mathrm{NCX} 1 \text { increased }[\mathrm{Na}] \mathrm{i} \text { and increased } \mathrm{Na} \text {, } \\
\mathrm{Ca} \text { exchange }\end{array}$ & $\begin{array}{l}\text { NCX1 TG worsened pathology in hindlimb } \\
\text { but improved pathology in diaphragm }\end{array}$ \\
\hline Slc8a1f/f with MLC-CRE $E^{33}$ & 2014 & $\mathrm{Sgcd}^{-/}$ & Not evaluated & $\begin{array}{l}\text { Deletion of NCX1 protein improved } \\
\text { histopathology at early time points }\end{array}$ \\
\hline \multicolumn{5}{|l|}{ EC-coupling } \\
\hline SERCA1 transgenic ${ }^{15}$ & 2011 & $S g c d^{-1-}$ and $m d x$ & $\begin{array}{l}\text { SERCA1 increased rate of SR-calcium } \\
\text { uptake }\end{array}$ & $\begin{array}{l}\text { SERCA1 TG decreased histopathology } \\
\text { and serum CK }\end{array}$ \\
\hline SERCA1 transgenic ${ }^{15}$ & 2011 & TRPC3 & Not evaluated & $\begin{array}{l}\text { SERCA1 TG rescued pathology mediated } \\
\text { by TRPC3 overexpression. }\end{array}$ \\
\hline AAV-SERCA2 $2^{15}$ & 2011 & $m d x$ & Not evaluated & $\begin{array}{l}\text { SERCA2a overexpression improved his- } \\
\text { topathology in gastrocnemius }\end{array}$ \\
\hline AAV-SERCA $1^{47}$ & 2010 & $m d x$ & Not evaluated & $\begin{array}{l}\text { SERCA1 improved force after eccentric } \\
\text { contraction and decreased } \\
\text { histopathology }\end{array}$ \\
\hline \multicolumn{5}{|l|}{ Mitochondrial } \\
\hline Ppif $^{-1-109}$ & 2008 & $\begin{array}{l}\text { mdx, Sgcd } \\
\text { and Lama2 }\end{array}$ & $\begin{array}{l}\text { Ppif deletion decreased mitochondrial } \\
\text { swelling }\end{array}$ & $\begin{array}{l}\text { Ppif } \\
\text { MD models. Improved strength in } \mathrm{Sgcd}^{-1}\end{array}$ \\
\hline Ppif $^{-1110}$ & 2009 & Col6a1 ${ }^{-1-}$ & $\begin{array}{l}\text { Ppif deletion decreased mitochondrial } \\
\text { depolarization }\end{array}$ & $\begin{array}{l}\text { Ppif }{ }^{-/} \text {decreased histopathology and } \\
\text { EBD uptake }\end{array}$ \\
\hline \multicolumn{5}{|l|}{ Calpain } \\
\hline Calpastatin transgenic ${ }^{23}$ & 2002 & $m d x$ & Not evaluated & $\begin{array}{l}\text { Calpastatin overexpression decreased } \\
\text { histopathology and EBD uptake }\end{array}$ \\
\hline
\end{tabular}


pathogenesis of MD. ${ }^{56-58}$ One study found that in dystrophindeficient myotubes, $\mathrm{IP}_{3} \mathrm{R}$ activation events were downregulated following transfection with minidystrophin, suggesting activation of this receptor is a downstream consequence of dystrophin deficiency. ${ }^{59}$ As inhibition of calcium sparks is already known to associate with reduced dystrophic pathology, it is plausible that a strategy targeting $I P_{3} R$ signaling could also benefit dystrophic muscle.

\section{Stretch and Store-Operated Calcium Entry}

The first evidence for aberrant calcium entry through the sarcolemma of diseased skeletal muscle came in 1988 by Turner et al. ${ }^{60}$ working with $m d x$ muscle fibers versus wild-type. Calcium currents were also observed to be elevated in $m d x$ diseased myotubes under conditions of mechanical stress. ${ }^{61}$ Previous studies have also observed that $m d x$ muscle fibers are more sensitive to cell death due to osmotic stress than wild-type muscle fibers. ${ }^{62}$ Interestingly, calcium entry is also increased in muscle fibers from $m d x$ mice under conditions of osmotic stress. ${ }^{14,63,64}$ In some of these studies, the observed current was inhibited by gadolidium and lanthanum, suggesting entry through channels of some sort. ${ }^{14,63,64}$ Finally, very large sodium currents also appear to be triggered by eccentric contraction, which could have implications for increased calcium influx due to sodium-calcium exchange dynamics. ${ }^{65}$

The activation of sodium and calcium entry by stretch provides a likely explanation for the damage and force decrement observed during eccentric contractions in $m d x$ mice. ${ }^{65,66}$ For example, muscle from wild-type mice show only a modest decrement in force after eccentric contractions, whereas muscle from $m d x$ mice exhibits large deficits in force, as well as membrane instability and loss of intracellular enzymes. ${ }^{67-69}$ Both the elevation of sodium and calcium and the damage incurred by eccentric contraction can be inhibited by gadolidium and lanthanum. ${ }^{66,70}$ Thus, in both intact muscles with eccentric stretch and in individual muscle fibers with osmotically mediated stress, calcium and sodium entry appear to be a primary mechanism that could directly lead to myofiber death.

The proximal mechanism linking sodium and calcium entry to membrane stress may be the recently described X-ROS (X-reactive oxygen species) pathway. ${ }^{71}$ It was also shown that calcium entry and ROS production can act in a positive feedback loop in $m d x$ muscle under conditions of osmotic stress, showing that calcium can amplify ROS production and vice versa. ${ }^{72}$ An alternative or potentially complementary explanation of stretch-induced calcium entry was suggested by the observation that Src can phosphorylate the transient receptor potential canonical-1 channel to give greater activity. ${ }^{73}$ Finally, calcium entry in skeletal muscle has also been associated with a process known as receptor-operated calcium entry (ROCE), such as through the P2X7 ATPactivated channel in association with phospholipase A2 signaling and diacylglycerol generation. ${ }^{74-76}$

\section{Genetic Evidence for the Calcium Hypothesis: TRP Channels and Orai1-Stim1}

Members of the TRPC family form heterotetrameric calcium and sodium entry channels that open in response to stretch, decreased SR-calcium content, and diacylglycerol ${ }^{77-79}$ (Figure 1). Vanderbrouk et al. ${ }^{80}$ first hypothesized that the increased cationic currents observed in dystrophic myofibers was due to TRPC channels. A later study by Millay et al. ${ }^{81}$ showed that store-operated calcium entry was increased in myofibers from $\mathrm{Sgcd}^{-1}$ mice, and that this activity was fully inhibited with a dominant-negative (dn) TRPC channel mutant in transgenic mice (Table 2). Furthermore, overexpression of wild-type TRPC3, which is known to increase calcium influx, generated abundant store-operated calcium entry that fully induced skeletal muscle pathology in vivo that was highly reminiscent of $\mathrm{MD}$ (Table 2). ${ }^{81}$ These results were actually profound and proved for the first time that increased calcium entry alone was capable of mediating essentially all the disease aspects of $\mathrm{MD}$ at the level of the myofiber in vivo. Conversely, overexpression of dnTRPC6 ameliorated dystrophic pathology in $\mathrm{Sgcd}^{-1}$ and $\mathrm{mdx}$ mice (Table 2). ${ }^{81}$ Thus, TRPC protein activity is both necessary and sufficient in the development of MD, although whether this channel generates a bonafide store-operated calcium entry process is still debated. ${ }^{82-84}$ These observations suggest that pharmacologic inhibitors against TRP channels could be of clinical value in MD (Figure 2).

Although TRPC channels can result in pathologic calcium entry, the more newly identified Stim and Orai proteins are thought to be the true mediators of store-operated calcium entry $^{85}$ (Figure 1). Recently, shRNA-mediated knockdown of Orai1 in vivo decreased store-operated calcium entry in myofibers from $m d x$ mice, also reducing muscle pathology. ${ }^{86}$ Other work using skeletal muscle transgenic strategies has shown that Stim1 overexpression, which markedly increases store-operated calcium entry, is pathogenic in skeletal muscle and induces fulminant MD (Table 2). ${ }^{87}$ Moreover, expression of a dominant-negative Orai1 protein by transgenesis in mouse skeletal muscle completely blocked Stim1 transgeneinduced MD disease, as well as reduced dystrophic disease in $\mathrm{SgCd}^{-1}$ mice (Table 2). ${ }^{87}$ The results of this study provide additional genetic proof in mice that calcium entry alone is sufficient to induce the entire process of MD. Furthermore, inhibition of these key pathogenic calcium entry pathways in $\mathrm{mdx}$ or $\mathrm{Sgcd}^{-1-}$ mice, such as through TRPC channels or Orai1-Stim1 complexes, can be strongly protective. Such results strongly suggest that calcium is the nodal mediator of myofiber necrosis and muscle degeneration in MD.

Alternatively, stretch-mediated calcium entry may also contribute to dystrophic pathology, such as through the transient receptor potential vanilloid (TRPV) family members. ${ }^{88}$ Trpv2 $^{-1}$ mice exhibited less-muscle pathology in the $m d x$ background, suggesting that the TRPV2 channel itself is a critical disease determinant (Table 2). ${ }^{89}$ Ho et al. ${ }^{90}$ determined that SKF-96365 and ruthenium red both inhibited stretch-activated currents in myofibers, which were also inhibited in Trpv4 ${ }^{-/}$mice. These results suggest that broad inhibitors of the greater TRP subfamilies could be an interesting approach to attempt in treating MD. Indeed, cationic antibiotics that broadly inhibit such channels, such as streptomycin, were shown to ameliorate aspects of muscle disease in $m d x$ mice. $^{66,91}$ Unfortunately, chronic use of streptomycin adversely affects the heart and diaphragm, likely through inhibition of mitochondrial ribosomal activity. ${ }^{92}$ 


\section{Na Homeostasis and Indirect Control of Calcium and MD}

The gradient of sodium ions across the plasma membrane is the basis for excitability and active transport, but this sodium gradient also serves as a co-regulator of calcium influx through the sodium-calcium exchanger (NCX), the sodiumpotassium-calcium exchanger, and the sodium-hydrogen exchanger (NHE1) (Figure 1). In living organisms, the activity of the sodium-potassium ATPase (NKA) generates and maintains the plasma membrane sodium gradient. Importantly, increased intracellular sodium concentration, as measured in dystrophic myofibers, can cause sodium-dependent exchangers to function in reverse-mode and thereby lead to a net increase in intracellular calcium levels through NCX and possibly contribute to pathologic effects of MD.

The first study that measured intracellular sodium in $m d x$ mice found a marked elevation of resting sodium levels from $13 \pm 3 \mathrm{mM}$ to $24 \pm 2 \mathrm{mM}$ in the gastrocnemius and from $13.0 \pm 0.3 \mathrm{mM}$ to $23.5 \pm 0.7 \mathrm{mM}$ in the diaphragm. ${ }^{93}$ Resting sodium levels of $11.5 \mathrm{mM}$ in wild-type myofibers and $22.5 \mathrm{mM}$ in $m d x$ myofibers were subsequently measured using a dyebased method, suggesting that the above results were accurate. ${ }^{94}$ Intracellular sodium measurements have also been extended to DMD patients using sodium 23 magnetic resonance imaging, which estimated a value of $25.4 \mathrm{mM}$ in control muscle versus $38.0 \mathrm{mM}$ in DMD patient muscle, suggesting that sodium overload may be an even larger component of the MD disease process in humans as they appear to have even higher basal levels. ${ }^{95,96}$ The critical concept here related to sodium is that not only could such an elevation cause cellular edema, but it would result in a secondary increase in basal calcium levels through the reversal of the NCX and NHE1 when the membrane is depolarized, augmenting calcium overload.

We observed that NCX1 protein levels were profoundly elevated in muscle tissue from dystrophic mice, which we modeled by generating transgenic mice to overexpress NCX1 in skeletal muscle. ${ }^{33}$ The overexpression of NCX1 induced a progressive dystrophic-like pathology in hindlimb skeletal muscle that was associated with greater reverse-mode calcium entry through this exchanger (Table 2). ${ }^{33}$ Not surprisingly, the overexpression of NCX1 exacerbated the pathology of the hindlimb musculature when crossed into the $\mathrm{mdx}$ and $\mathrm{Sgcd}^{-/}$mouse models, again by presumably increasing calcium influx. ${ }^{33}$ Finally, the deletion of endogenous NCX1 (S/c8a gene) specifically in skeletal muscle ameliorated the early pathological profile of MD disease in $\mathrm{SgCd}^{-1}$ mice when this type of reverse-mode calcium entry normally occurs and contributes to pathology. ${ }^{33}$ Thus, inhibitors that either selectively reduce intracellular sodium levels so that NCX remains in forward mode operation, or inhibitors against reverse-mode NCX activity, could be therapeutics to evaluate in human clinical trials. Indeed, ranolazine, a general sodium-lowering drug reduced muscle pathology in $\mathrm{Sgcd}^{-1-}$ mice ${ }^{33}$ (Figure 2). It is interesting to note that because of the thermodynamics of sodium and calcium exchange mediated by NCX1, reversal will occur in dystrophic muscle at a more polarized membrane potential because intracellular sodium is elevated (calculations performed based on formula from ref. 97 not shown).
Another recent study looked at the role of the NHE1 in MD, in part because intracellular $\mathrm{pH}$ was observed to be elevated in dystrophic muscle. ${ }^{98}$ Iwata et al. showed that both sodium and calcium were elevated with $\mathrm{MD}$, and that treatment of dystrophic myotubes with inhibitors of NHE1 decreased sodium and use of these inhibitors in vivo decreased dystrophic pathology when administered to $m d x$ mice or BIO14.6 hamsters. ${ }^{98}$ These results are consistent with the NCX1 data discussed above and again suggest that sodium elevation is a considerable disease mechanism that can underlie secondary calcium entry, leading to myofiber necrosis and muscle degeneration in MD.

\section{Calcium-Activated Protease Activity}

The calpains are calcium-activated proteases that are critical to muscle development and homeostasis (Figure 1). Increased calpain activity can exacerbate pathology in MD by cleaving critical intracellular proteins, and not surprisingly, calpain activity is increased in muscle from $m d x$ mice. ${ }^{99}$ To test the involvement of calpains in the MD disease process, Spencer et al. ${ }^{23}$ overexpressed the inhibitory protein calpastatin in the $m d x$ mouse, which ameliorated dystrophic pathology (Table 2). Interestingly, calpastatin overexpressing mice had less necrotic lesions in histologic sections, but membrane instability was still present. ${ }^{23}$ A subsequent study using leupeptin, a protease inhibitor with some specificity to calpains, found less pathology in dystrophic mice. ${ }^{100}$ Recently, Briguet et al. ${ }^{101}$ repeated overexpression of calpastatin in the $m d x$ mouse and failed to observe a difference in muscle pathology; however, when they inhibited both calpains and the $20 \mathrm{~S}$ proteasome with SNT198438, they were able to ameliorate the dystrophic phenotype. Despite minor inconsistencies, the overall conclusion is that calcium elevation in MD participates in calpain proteolytic activity, which contributes to myofiber dysfunction and necrosis and hence could be pharmacologically inhibited to treat MD (Figure 2).

\section{MPTP Opening}

Calcium- and ROS-induced MPTP-opening results in depolarization and swelling of the mitochondria leading to loss of energy production and ultimately the rupture of this organelle and myofiber necrosis (Figure 1). The MPTP is a multiprotein complex found within the inner membrane of mitochondria regulated by the prolyl isomerase cyclophilin D (CypD, encoded by Ppif gene). Recent data have shown that the pore itself is most likely comprised of the mitochondrial $F_{1} F_{O}$ ATP synthase, which spans the inner mitochondrial membrane. ${ }^{102,103}$ CypD sensitizes the pore to opening in response to elevated ROS or calcium. Indeed, mice lacking the gene for CypD show reduced MPTP opening to various stimuli and general protection from cardiac and brain ischemic injury in vivo. ${ }^{104}$

By using mitochondrial localized aequorin proteins it was also shown that mitochondrial calcium is increased in $m d x$ myotubes. ${ }^{35}$ The first evidence that calcium overload of the mitochondrial may actually happen in vivo was provided through the study of a mouse model of MD owing to a 
deficiency in Col6a 1. ${ }^{105,106}$ Early work in the Col6a1 ${ }^{-/-}$mice defined mitochondrial deficiency and apoptosis as hallmarks of this disease, clearly linking mitochondrial dysfunction to this muscle disease. ${ }^{106}$ Furthermore, they implicated CypD by finding that the mitochondrial dysfunction observed in vitro and the cell death observed in vivo was inhibited by the CypD inhibitor cyclosporine A. ${ }^{105,107}$ The improvement in mitochondrial function and reduction in cell death was subsequently shown in patients with Ullrich's congenital $\mathrm{MD}$, and this therapy was tolerated even after long-term follow-up. ${ }^{108}$

At about the same time we reported that muscle from $m d x$ and $\mathrm{SgCd}^{-1-}$ mice had swollen mitochondria, suggesting that MPTP opening is a pathogenic occurrence in MD. ${ }^{109}$ Indeed, deletion of the Ppif gene reduced mitochondrial swelling and led to a profound reduction in the dystrophic phenotype of $\mathrm{SgCd}^{-1-}$ mice and the $\mathrm{Lama2}^{-/}$mice, the latter of which is a model of congenital MD due to laminina2 deficiency (Table 2). ${ }^{109}$ Ppif deletion also led to decreased muscle pathology and restoration of mitochondrial function in the Col6a1 mouse model as deletion of MD. ${ }^{110}$ The fact that four separate models of MD with potentially divergent proximal mechanisms of disease were each rescued suggested that MPTP opening due to calcium dysregulation may be the final common pathway for multiple muscle diseases. Indeed, Debio-025, a CypD inhibitor, also ameliorated dystrophic pathology in $m d x$ mice and an Ulrich congenital MD mouse model $^{105,109,111-113}$ (Figure 2). These results further implicate calcium as the primary second messenger in mediating myofiber necrosis and muscle degeneration in MD.

\section{Novel Medical Treatments Based on the Calcium Hypothesis}

The calcium hypothesis of MD suggests a number of potential treatment options, only a small number of which have been tested to date (Figure 2). Preclinical efficacy in the mouse has been shown for inhibitors of the MPTP (Debio-025), NHE1 (cariporide and 5-( $N$-ethyl- $N$-isopropyl)-amiloride), ryanodine leak inhibitors (S107), indirect SERCA activators (BGP-15), stretch-activated channel inhibitors (streptomycin), L-type calcium channel inhibitors (verapamil, diltiazem, and nifedipine), TRPC channel inhibitors, inhibitors of X-ROS pathway (colchicine), and reverse-mode NCX inhibitors (ranolazine) or other general inhibitors that reduce intracellular sodium (ranolazine). ${ }^{33,39,41-43,49,53-55,71,91,92,98,109,114}$ Many more inhibitors have yet to be tested including novel TPRC/TRPV inhibitors, SERCA activators, and other inhibitors of NCX1 including KB-R7943 and SEA0400 ${ }^{115-123}$ (Figure 2).

Alternatively, gene therapy approaches are also rapidly maturing and could be translated into the clinic, such as SERCA2 viral vectors, which are now in phase II/III trials for human heart failure. ${ }^{48}$ SERCA gene therapy is particularly exciting to consider given the large magnitude of effect associated with increasing SERCA activity in ameliorating disease in multiple mouse models of MD, results observed across independent laboratories. ${ }^{15,47}$ Another possibility could be adenoviral gene therapy to express dnTRPC or dnTRPV channels selectively in skeletal muscle, which appears to reduce or eliminate most of store-operated, stretch-dependent, and even ROCE pathways that are known to occur in dystrophic skeletal muscle.

\section{Summary and Implications of the Calcium Hypothesis}

The calcium hypothesis has matured greatly over the past decade; thanks to genetic models that have proven beyond a doubt the importance of calcium overload/dysregulation in mediating myofiber necrosis and MD pathogenesis. Clearly, calcium homeostasis can be corrected at multiple levels to positively impact MD, including at the level of the SR, the plasma membrane, and the mitochondria. It seems logical, given the known mechanical defects within the dystrophic plasma membrane that alterations in calcium and sodium levels likely stems from excessive activation of various channels and exchangers that then leads to alterations in SR-calcium handling and mitochondrial calcium loading. For example, it is easy to see how slowed calcium reuptake to the SR could lead to greater mitochondrial uptake and MPTP opening, which in turn could lead to reduced energy production and failure of active transport, thereby producing even greater sodium and calcium overload and eventually cellular necrosis. Although the data we presented in genetically modified mouse models makes a compelling case for the calcium hypothesis of disease pathogenesis in MD as originally proposed by Wrogemann, questions still remain. However, in the meantime we believe that the animal data are more than compelling enough to spur new clinical trials aimed at correcting defects in calcium handling and basal calcium overload, both with pharmacologic agents and with gene therapeutic approaches.

\section{Conflict of Interest}

The authors declare no conflict of interest.

Acknowledgements. This work was supported by grants from the National Institutes of Health (to JDM). JDM is an investigator of the Howard Hughes Medical Institute.

\section{Author contributions}

ARB and JDM wrote the manuscript.

1. Emery AE. Population frequencies of inherited neuromuscular diseases-a world survey. Neuromuscul Dis 1991; 1: 19-29.

2. Durbeej M, Campbell KP. Muscular dystrophies involving the dystrophin-glycoprotein complex: an overview of current mouse models. Curr Opin Genet Dev 2002; 12 : 349-361.

3. Bansal D, Miyake K, Vogel SS, Groh S, Chen CC, Williamson R et al. Defective membrane repair in dysferlin-deficient muscular dystrophy. Nature 2003; 423: 168-172.

4. Wrogemann K, Pena SD. Mitochondrial calcium overload: a general mechanism for cellnecrosis in muscle diseases. Lancet 1976; 1: 672-674.

5. McComas AJ, Sica RE, Currie S. An electrophysiological study of Duchenne dystrophy. J Neurol Neurosurg Psychiatry 1971; 34: 461-468.

6. McComas AJ, Thomas HC. A study of the muscle twitch in the Duchenne type muscular dystrophy. J Neurol Sci 1968; 7: 309-312.

7. Wood DS, Sorenson MM, Eastwood AB, Charash WE, Reuben JP. Duchenne dystrophy: abnormal generation of tension and $\mathrm{Ca}++$ regulation in single skinned fibers. Neurology 1978; 28: 447-457.

8. Williams DA, Head SI, Lynch GS, Stephenson DG. Contractile properties of skinned muscle fibres from young and adult normal and dystrophic (mdx) mice. J Physiol 1993; 460: 51-67. 
9. Sacco $\mathrm{P}$, Jones DA, Dick JR, Vrbova G. Contractile properties and susceptibility to exercise-induced damage of normal and mdx mouse tibialis anterior muscle. Clin Sci (Lond) 1992; 82: 227-236.

10. Quinlan JG, Johnson SR, McKee MK, Lyden SP. Twitch and tetanus in mdx mouse muscle. Muscle Nerve 1992; 15: 837-842.

11. Divet A, Huchet-Cadiou C. Sarcoplasmic reticulum function in slow- and fast-twitch skeletal muscles from mdx mice. Pflugers Arch 2002; 444: 634-643.

12. Nicolas-Metral V, Raddatz E, Kucera P, Ruegg UT. Mdx myotubes have normal excitability but show reduced contraction-relaxation dynamics. J Mus Res Cell Motil 2001; 22: 69-75.

13. Head SI. Membrane potential, resting calcium and calcium transients in isolated muscle fibres from normal and dystrophic mice. J Physiol 1993; 469: 11-19.

14. Tutdibi $\mathrm{O}$, Brinkmeier $\mathrm{H}$, Rudel $\mathrm{R}$, Fohr $\mathrm{KJ}$. Increased calcium entry into dystrophin-deficient muscle fibres of MDX and ADR-MDX mice is reduced by ion channel blockers. J PhysiolLondon 1999; 515: 859-868.

15. Goonasekera SA, Lam CK, Millay DP, Sargent MA, Hajjar RJ, Kranias EG et al. Mitigation of muscular dystrophy in mice by SERCA overexpression in skeletal muscle. J Clin Invest 2011; 121: 1044-1052.

16. Leberer E, Hartner KT, Pette D. Postnatal development of Ca2+-sequestration by the sarcoplasmic reticulum of fast and slow muscles in normal and dystrophic mice. Eur $J$ Biochem 1988; 174: 247-253.

17. Landi N, Nassi P, Liguri G, Bobbi S, Sbrilli C, Marconi G. Sarcoplasmic reticulum Ca2+-ATPase and acylphosphatase activities in muscle biopsies from patients with Duchenne muscular dystrophy. Clin Chim Acta 1986; 158: 245-251.

18. Woods CE, Novo D, DiFranco M, Vergara JL. The action potential-evoked sarcoplasmic reticulum calcium release is impaired in mdx mouse muscle fibres. J Physiol-London 2004; 557: $59-75$.

19. Gómez J, Neco P, Difranco M, Vergara JL. Calcium release domains in mammalian skeletal muscle studied with two-photon imaging and spot detection techniques. $J$ Gen Physiol 2006; 127: 623-637.

20. Hoffman EP, Knudson CM, Campbell KP, Kunkel LM. Subcellular fractionation of dystrophin to the triads of skeletal-muscle. Nature 1987; 330: 754-758.

21. Karch J, Molkentin JD. Identifying the components of the elusive mitochondrial permeability transition pore. Proc Natl Acad Sci USA 2014; 111: 10396-10397.

22. Bernardi $P$, Di Lisa F. The mitochondrial permeability transition pore: molecular nature and role as a target in cardioprotection. J Mol Cell Cardiol 2015; 78: 100-106.

23. Spencer MJ, Mellgren RL. Overexpression of a calpastatin transgene in mdx muscle reduces dystrophic pathology. Hum Mol Gen 2002; 11: 2645-2655.

24. Turner PR, Schultz R, Ganguly B, Steinhardt RA. Proteolysis results in altered leak channel kinetics and elevated free calcium in mdx muscle. J Membr Biol 1993; 133: 243-251.

25. Bodensteiner JB, Engel AG. Intracellular calcium accumulation in Duchenne dystrophy and other myopathies: a study of 567,000 muscle fibers in 114 biopsies. Neurology 1978; 28 439-446.

26. Maunder-Sewry CA, Gorodetsky R, Yarom R, Dubowitz V. Element analysis of skeletal muscle in Duchenne muscular dystrophy using $\mathrm{x}$-ray fluorescence spectrometry. Muscle Nerve 1980; 3: 502-508.

27. Jackson MJ, Jones DA, Edwards RH. Measurements of calcium and other elements in muscle biopsy samples from patients with Duchenne muscular dystrophy. Clin Chim Acta 1985; 147: 215-221.

28. Turner PR, Westwood T, Regen CM, Steinhardt RA. Increased protein degradation results from elevated free calcium levels found in muscle from mdx mice. Nature 1988; 335 735-738.

29. Gailly P, Boland B, Himpens B, Casteels R, Gillis JM. Critical evaluation of cytosolic calcium determination in resting muscle fibres from normal and dystrophic $(\mathrm{mdx})$ mice. Cell Calcium 1993; 14: 473-483.

30. Collet C, Allard B, Tourneur Y, Jacquemond V. Intracellular calcium signals measured with indo-1 in isolated skeletal muscle fibres from control and mdx mice. J Physiol 1999; 520(Pt 2): 417-429.

31. Altamirano F, López JR, Henríquez C, Molinski T, Allen PD, Jaimovich E. Increased resting intracellular calcium modulates NF-? B-dependent inducible nitric-oxide synthase gene expression in dystrophic mdx skeletal myotubes. J Biol Chem 2012; 287: 20876-20887.

32. Altamirano F, Valladares D, Henriquez-Olguin C, Casas M, Lopez JR, Allen PD et al. Nifedipine treatment reduces resting calcium concentration, oxidative and apoptotic gene expression, and improves muscle function in dystrophic mdx mice. PLoS One 2013; 8: e81222.

33. Burr AR, Millay DP, Goonasekera SA, Park KH, Sargent MA, Collins J et al. Na+ dysregulation coupled with $\mathrm{Ca} 2+$ entry through NCX1 promotes muscular dystrophy in mice. Mol Cell Biol 2014; 34: 1991-2002.

34. Altamirano F, Lopez JR, Henriquez C, Molinski T, Allen PD, Jaimovich E. Increased resting intracellular calcium modulates NF-kappaB-dependent inducible nitric-oxide synthase gene expression in dystrophic mdx skeletal myotubes. J Biol Chem 2012; 287: 20876-20887.

35. Robert V, Massimino ML, Tosello V, Marsault R, Cantini M, Sorrentino V et al. Alteration in calcium handling at the subcellular level in mdx myotubes. J Biol Chem 2001; 276: 4647-4651.

36. Mallouk $\mathrm{N}$, Allard $\mathrm{B}$. $\mathrm{Ca}(2+)$ influx and opening of $\mathrm{Ca}(2+)$-activated $\mathrm{K}(+)$ channels in muscle fibers from control and mdx mice. Biophys J 2002; 82: 3012-3021.
37. Han R, Grounds MD, Bakker AJ. Measurement of sub-membrane [Ca2+] in adult myofibers and cytosolic $[\mathrm{Ca} 2+]$ in myotubes from normal and mdx mice using the $\mathrm{Ca} 2+$ indicator FFP-18. Cell Calcium 2006; 40: 299-307.

38. Shannon TR, Wang F, Puglisi J, Weber C, Bers DM. A mathematical treatment of integrated Ca dynamics within the ventricular myocyte. Biophys J 2004; 87: 3351-3371.

39. Pernice W, Beckmann R, Ketelsen UP, Frey M, Schmidt-Redemann B, Haap KP et al. A double-blind placebo controlled trial of diltiazem in Duchenne dystrophy. Klinische Wochenschrift 1988; 66: 565-570.

40. Phillips MF, Quinlivan R. Calcium antagonists for Duchenne muscular dystrophy. Cochrane Database Syst Rev 2008: CD004571.

41. Dick DJ, Gardner-Medwin D, Gates PG, Gibson M, Simpson JM, Walls TJ. A trial of flunarizine in the treatment of Duchenne muscular dystrophy. Muscle Nerve 1986; 9: 349-354

42. Moxley RT 3rd, Brooke MH, Fenichel GM, Mendell JR, Griggs RC, Miller JP et al. Clinical investigation in Duchenne dystrophy. VI. Double-blind controlled trial of nifedipine. Muscle Nerve 1987; 10: 22-33.

43. Emery AEH, Skinner R, Howden LC, Matthews MB. Verapamil in Duchenne musculardystrophy. Lancet 1982; 1: 559-559.

44. Bertorini TE, Palmieri GM, Griffin JW, Igarashi M, McGee J, Brown R et al. Effect of chronic treatment with the calcium antagonist diltiazem in Duchenne muscular dystrophy. Neurology 1988; 38: 609-613.

45. Neto HS, Matsumura CY, Marques MJ. Diltiazem and verapamil protect dystrophindeficient muscle fibers of $\mathrm{mdx}$ mice from degeneration: Potential role in calcium buffering and sarcolemmal stability. Neuromuscul Disord 2008; 18: 812-812.

46. Kargacin ME, Kargacin GJ. The sarcoplasmic reticulum calcium pump is functionally altered in dystrophic muscle. Biochim Biophys Acta 1996; 1290: 4-8.

47. Morine KJ, Sleeper MM, Barton ER, Sweeney HL. Overexpression of SERCA1a in the mdx diaphragm reduces susceptibility to contraction-induced damage. Hum Gene Ther 2010; 21: 1735-1739.

48. Jaski BE, Jessup ML, Mancini DM, Cappola TP, Pauly DF, Greenberg B et al. Calcium upregulation by percutaneous administration of gene therapy in cardiac disease (CUPID Trial), a first-in-human phase 1/2 clinical trial. J Card Fail 2009; 15: 171-181.

49. Gehrig SM, van der Poel C, Sayer TA, Schertzer JD, Henstridge DC, Church JE et al. Hsp72 preserves muscle function and slows progression of severe muscular dystrophy. Nature 2012; 484: 394-398.

50. Wang X, Weisleder N, Collet C, Zhou JS, Chu Y, Hirata Y et al. Uncontrolled calcium sparks act as a dystrophic signal for mammalian skeletal muscle. Nat Cell Biol 2005; 7 525-530.

51. Weisleder N, Wang X, Collet C, Zhou JS, Chu Y, Hirata Y et al. Stress-induced uncontrolled calcium sparks as dystrophic signals in mammalian skeletal muscle. Biophys $J 2005 ; \mathbf{8 8}$ 534a-535a.

52. Aracena P, Tang W, Hamilton SL, Hidalgo C. Effects of S-glutathionylation and S-nitrosylation on calmodulin binding to triads and FKBP12 binding to type 1 calcium release channels. Antioxid Redox Signal 2005; 7: 870-881.

53. Bellinger AM, Reiken S, Dura M, Murphy PW, Deng SX, Landry DW et al. Remodeling of ryanodine receptor complex causes 'leaky' channels: a molecular mechanism for decreased exercise capacity. Proc Natl Acad Sci USA 2008; 105: 2198-2202.

54. Bellinger AM, Reiken S, Carlson C, Mongillo M, Liu XP, Rothman L et al. Hypernitrosylated ryanodine receptor calcium release channels are leaky in dystrophic muscle. Nat Med 2009; 15: 325-330.

55. Andersson DC, Meli AC, Reiken S, Betzenhauser MJ, Umanskaya A, Shiomi T et al. Leaky ryanodine receptors in beta-sarcoglycan deficient mice: a potential common defect in muscular dystrophy. Skelet Muscle 2012; 2: 9.

56. Mondin L, Balghi H, Constantin B, Cognard C, Sebille S. Negative modulation of inositol 1,4,5-trisphosphate type 1 receptor expression prevents dystrophin-deficient muscle cells death. Am J Physiol Cell Physiol 2009; 297: C1133-C1145.

57. Balghi H, Sebille S, Constantin B, Patri S, Thoreau V, Mondin L et al. Mini-dystrophin expression down-regulates overactivation of $\mathrm{G}$ protein-mediated IP3 signaling pathway in dystrophin-deficient muscle cells. J Gen Physiol 2006; 127: 171-182.

58. Tjondrokoesoemo A, Li N, Lin PH, Pan Z, Ferrante CJ, Shirokova N et al. Type 1 Inositol (1,4,5)-trisphosphate receptor activates ryanodine receptor 1 to mediate calcium spark signaling in adult mammalian skeletal muscle. J Biol Chem 2013; 288: 2103-2109.

59. Balghi H, Sebille S, Mondin L, Cantereau A, Constantin B, Raymond G et al. Minidystrophin expression down-regulates IP3-mediated calcium release events in resting dystrophin-deficient muscle cells. J Gen Physiol 2006; 128: 219-230.

60. Turner PR, Fong PY, Denetclaw WF, Steinhardt RA. Increased calcium influx in dystrophic muscle. J Cell Biol 1991; 115: 1701-1712.

61. Franco Jr A, Lansman JB. Calcium entry through stretch-inactivated ion channels in $\mathrm{mdx}$ myotubes. Nature 1990; 344: 670-673.

62. Menke A, Jockusch H. Decreased osmotic stability of dystrophin-less muscle-cells from the Mdx mouse. Nature 1991; 349: 69-71.

63. Franco Jr A, Winegar BD, Lansman JB. Open channel block by gadolinium ion of the stretch-inactivated ion channel in mdx myotubes. Biophys $J$ 1991; 59: 1164-1170.

64. Leijendekker WJ, Passaquin AC, Metzinger L, Ruegg UT. Regulation of cytosolic calcium in skeletal muscle cells of the mdx mouse under conditions of stress. Br J Pharmacol 1996; 118: $611-616$. 
65. Yeung EW, Ballard HJ, Bourreau JP, Allen DG. Intracellular sodium in mammalian muscle fibers after eccentric contractions. J Appl Physiol 2003; 94: 2475-2482.

66. Yeung EW, Whitehead NP, Suchyna TM, Gottlieb PA, Sachs F, Allen DG. Effects of stretchactivated channel blockers on [Ca2+]i and muscle damage in the mdx mouse. J Physio 2005; 562: 367-380.

67. Moens $P$, Baatsen PHWW, Marechal G. Increased susceptibility of Edl muscles from Mdx mice to damage-induced by contractions with stretch. J Mus Res Cell Motil 1993; 14 446-451.

68. Petrof BJ, Shrager JB, Stedman HH, Kelly AM, Sweeney HL. Dystrophin protects the sarcolemma from stresses developed during muscle contraction. Proc Natl Acad Sci USA 1993; 90: 3710-3714.

69. Childers MK, Okamura CS, Bogan DJ, Bogan JR, Petroski GF, McDonald K et al. Eccentric contraction injury in dystrophic canine muscle. Arch Phys Med Rehab 2002; 83 1572-1578.

70. Yeung EW, Head SI, Allen DG. Gadolinium reduces short-term stretch-induced muscle damage in isolated mdx mouse muscle fibres. J Physiol-London 2003; 552: 449-458.

71. Khairallah RJ, Shi GL, Sbrana F, Prosser BL, Borroto C, Mazaitis MJ et al. Microtubules underlie dysfunction in Duchenne muscular dystrophy. Sci Signal 2012; 5: ra56.

72. Shkryl VM, Martins AS, Ullrich ND, Nowycky MC, Niggli E, Shirokova N. Reciprocal amplification of ROS and $\mathrm{Ca} 2+$ signals in stressed $\mathrm{mdx}$ dystrophic skeletal muscle fibers. Pflugers Arch 2009; 458: 915-928.

73. Gervasio OL, Whitehead NP, Yeung EW, Phillips WD, Allen DG. TRPC1 binds to caveolin-3 and is regulated by Src kinase - role in Duchenne muscular dystrophy. J Cell Sci2008; 121 2246-2255.

74. Young CN, Brutkowski W, Lien CF, Arkle S, Lochmuller $\mathrm{H}$, Zablocki $\mathrm{K}$ et al. P2X7 purinoceptor alterations in dystrophic $\mathrm{mdx}$ mouse muscles: relationship to pathology and potential target for treatment. J Cell Mol Med 2012; 16: 1026-1037.

75. Boittin FX, Petermann O, Hirn C, Mittaud P, Dorchies OM, Roulet E et al. Ca2 +-independent phospholipase $\mathrm{A} 2$ enhances store-operated $\mathrm{Ca} 2+$ entry in dystrophic skeletal muscle fibers. J Cell Sci 2006; 119: 3733-3742.

76. Harvey AL, Hider RC, Khader F. Effect of phospholipase A on actions of cobra venom cardiotoxins on erythrocytes and skeletal muscle. Biochim Biophys Acta 1983; 728 215-221.

77. Hofmann T, Obukhov AG, Schaefer M, Harteneck C, Gudermann T, Schultz G. Direct activation of human TRPC6 and TRPC3 channels by diacylglycerol. Nature 1999; 397 259-263.

78. Liao Y, Erxleben C, Abramowitz J, Flockerzi V, Zhu MX, Armstrong DL et al. Functional interactions among Orai1, TRPCs, and STIM1 suggest a STIM-regulated heteromeric Orai/ TRPC model for SOCE/lcrac channels. Proc Natl Acad Sci USA 2008; 105: 2895-2900.

79. Maroto R, Raso A, Wood TG, Kurosky A, Martinac B, Hamill OP. TRPC1 forms the stretch activated cation channel in vertebrate cells. Nat Cell Biol 2005; 7: 179-185.

80. Vandebrouck C, Martin D, Colson-Van Schoor M, Debaix H, Gailly P. Involvement of TRPC in the abnormal calcium influx observed in dystrophic ( $\mathrm{mdx}$ ) mouse skeletal muscle fibers. J Cell Biol 2002; 158: 1089-1096.

81. Millay DP, Goonasekera SA, Sargent MA, Maillet M, Aronow BJ, Molkentin JD. Calcium influx is sufficient to induce muscular dystrophy through a TRPC-dependent mechanism. Proc Natl Acad Sci USA 2009; 106: 19023-19028.

82. Edwards JN, Friedrich O, Cully TR, von Wegner F, Murphy RM, Launikonis BS. Upregulation of store-operated $\mathrm{Ca} 2+$ entry in dystrophic mdx mouse muscle. Am J Physio Cell Physiol 2010; 299: C42-C50.

83. Brechard S, Melchior C, Plancon S, Schenten V, Tschirhart EJ. Store-operated Ca2+ channels formed by TRPC1, TRPC6 and Orai1 and non-store-operated channels formed by TRPC3 are involved in the regulation of NADPH oxidase in HL-60 granulocytes. Cell Calcium 2008; 44: 492-506.

84. Antigny $\mathrm{F}$, Jousset $\mathrm{H}$, Konig $\mathrm{S}$, Frieden $\mathrm{M}$. Thapsigargin activates $\mathrm{Ca} 2+$ entry both by store-dependent, STIM1/Orai1-mediated, and store-independent, TRPC3/ PLC/PKC-mediated pathways in human endothelial cells. Cell Calcium 2011; 49 115-127.

85. Dirksen RT. Checking your SOCCs and feet: the molecular mechanisms of Ca2+ entry in skeletal muscle. J Physiol 2009; 587: 3139-3147.

86. Zhao X, Moloughney JG, Zhang S, Komazaki S, Weisleder N. Orai1 mediates exacerbated $\mathrm{Ca}(2+)$ entry in dystrophic skeletal muscle. PLoS One 2012; 7: e49862.

87. Goonasekera SA, Davis J, Kwong JQ, Accornero F, Wei-Lapierre L, Sargent MA et al. Enhanced $\mathrm{Ca} 2+$ influx from STIM1-Orai1 induces muscle pathology in mouse models of muscular dystrophy. Hum Mol Gen 2014; 23: 3706-3716.

88. Iwata Y, Katanosaka Y, Arai Y, Shigekawa M, Wakabayashi S. Dominant-negative inhibition of Ca2+ influx via TRPV2 ameliorates muscular dystrophy in animal models. Hum Mol Gen 2009; 18: 824-834.

89. Zanou N, Iwata Y, Schakman O, Lebacq J, Wakabayashi S, Gailly P. Essential role of TRPV2 ion channel in the sensitivity of dystrophic muscle to eccentric contractions. FEBS Lett 2009; 583: 3600-3604.

90. Ho TC, Horn NA, Huynh T, Kelava L, Lansman JB. Evidence TRPV4 contributes to mechanosensitive ion channels in mouse skeletal muscle fibers. Channels 2012; 6 : 246-254.

91. Whitehead NP, Streamer M, Lusambili LI, Sachs F, Allen DG. Streptomycin reduces stretch-induced membrane permeability in muscles from mdx mice. Neuromuscul Disord 2006; 16: 845-854.
92. Jorgensen LH, Blain A, Greally E, Laval SH, Blamire AM, Davison BJ et al. Long-term blocking of calcium channels in mdx mice results in differential effects on heart and skeletal muscle. Am J Pathol 2011; 178: 273-283.

93. Dunn JF, Bannister N, Kemp GJ, Publicover SJ. Sodium is elevated in mdx muscles: ionic interactions in dystrophic cells. J Neurol Sci 1993; 114: 76-80.

94. Miles MT, Cottey E, Cottey A, Stefanski C, Carlson CG. Reduced resting potentials in dystrophic $(\mathrm{mdx})$ muscle fibers are secondary to NF-kappaB-dependent negative modulation of ouabain sensitive Na+-K+ pump activity. J Neurol Sci 2011; 303: 53-60.

95. Weber MA, Nagel AM, Jurkat-Rott K, Lehmann-Horn F. Sodium (23Na) MRI detects elevated muscular sodium concentration in Duchenne muscular dystrophy. Neurology 2011; 77: 2017-2024.

96. Weber MA, Nagel AM, Wolf MB, Jurkat-Rott K, Kauczor HU, Semmler W et al. Permanent muscular sodium overload and persistent muscle edema in Duchenne muscular dystrophy: a possible contributor of progressive muscle degeneration. J Neurol 2012; 259: 2385-2392.

97. Weber CR, Ginsburg KS, Philipson KD, Shannon TR, Bers DM. Allosteric regulation of $\mathrm{Na} / \mathrm{Ca}$ exchange current by cytosolic $\mathrm{Ca}$ in intact cardiac myocytes. J Gen Physiol 2001; 117: 119-131.

98. Iwata $\mathrm{Y}$, Katanosaka $\mathrm{Y}$, Hisamitsu T, Wakabayashi S. Enhanced $\mathrm{Na}+/ \mathrm{H}+$ exchange activity contributes to the pathogenesis of muscular dystrophy via involvement of $\mathrm{P} 2$ receptors. Am $J$ Pathol 2007; 171: 1576-1587.

99. Spencer MJ, Croall DE, Tidball JG. Calpains are activated in necrotic fibers from $\mathrm{mdx}$ dystrophic mice. J Biol Chem 1995; 270: 10909-10914.

100. Ishihara K, Ziats NP, Tierney BP, Nakabayashi N, Anderson JM. Protein adsorption from human plasma is reduced on phospholipid polymers. J Biomed Mater Res 1991; 25: 1397-1407.

101. Briguet A, Erb M, Courdier-Fruh I, Barzaghi P, Santos G, Herzner H et al. Effect of calpain and proteasome inhibition on $\mathrm{Ca} 2+$-dependent proteolysis and muscle histopathology in the mdx mouse. FASEB J 2008; 22: 4190-4200.

102. Giorgio V, von Stockum S, Antoniel M, Fabbro A, Fogolari F, Forte M et al. Dimers of mitochondrial ATP synthase form the permeability transition pore. Proc Natl Acad Sci USA 2013; 110: 5887-5892.

103. Alavian KN, Beutner G, Lazrove E, Sacchetti S, Park HA, Licznerski $P$ et al. An uncoupling channel within the c-subunit ring of the F1FO ATP synthase is the mitochondrial permeability transition pore. Proc Natl Acad Sci USA 2014; 111: 10580-10585

104. Javadov S, Kuznetsov A. Mitochondrial permeability transition and cell death: the role of cyclophilin d. Front Physiol 2013; 4: 76.

105. Angelin A, Tiepolo T, Sabatelli P, Grumati P, Bergamin N, Golfieri C et al. Mitochondrial dysfunction in the pathogenesis of Ullrich congenital muscular dystrophy and prospective therapy with cyclosporins. Proc Natl Acad Sci USA 2007; 104 : 991-996.

106. Irwin WA, Bergamin N, Sabatelli $P$, Reggiani $C$, Megighian A, Merlini L et al. Mitochondrial dysfunction and apoptosis in myopathic mice with collagen VI deficiency. Nat Genet 2003; 35: 367-371.

107. Merlini L, Angelin A, Tiepolo T, Braghetta P, Sabatelli P, Zamparelli A et al. Cyclosporin A corrects mitochondrial dysfunction and muscle apoptosis in patients with collagen $\mathrm{VI}$ myopathies. Proc Natl Acad Sci USA 2008; 105: 5225-5229.

108. Merlini L, Sabatelli P, Armaroli A, Gnudi S, Angelin A, Grumati P et al. Cyclosporine A in Ullrich congenital muscular dystrophy: long-term results. Oxid Med Cell Longev 2011; 2011: 139194.

109. Millay DP, Sargent MA, Osinska H, Baines CP, Barton ER, Vuagniaux G et al. Genetic and pharmacologic inhibition of mitochondrial-dependent necrosis attenuates muscular dystrophy. Nat Med 2008; 14: 442-447.

110. Palma E, Tiepolo T, Angelin A, Sabatelli P, Maraldi NM, Basso E et al. Genetic ablation of cyclophilin $\mathrm{D}$ rescues mitochondrial defects and prevents muscle apoptosis in collagen $\mathrm{VI}$ myopathic mice. Hum Mol Gen 2009; 18: 2024-2031.

111. Wissing ER, Millay DP, Vuagniaux G, Molkentin JD. Debio-025 is more effective than prednisone in reducing muscular pathology in mdx mice. Neuromuscul Disord 2010; 20: 753-760.

112. Reutenauer J, Dorchies OM, Patthey-Vuadens O, Vuagniaux G, Ruegg UT. Investigation of Debio 025, a cyclophilin inhibitor, in the dystrophic mdx mouse, a model for Duchenne muscular dystrophy. Br J Pharmacol 2008; 155: 574-584.

113. Tiepolo $T$, Angelin A, Palma E, Sabatelli $P$, Merlini L, Nicolosi $L$ et al. The cyclophilin inhibitor Debio 025 normalizes mitochondrial function, muscle apoptosis and ultrastructural defects in Col6a1-/- myopathic mice. Br J Pharmacol 2009; 157 : 1045-1052.

114. Toifl K, Presterl E, Graninger W. Lack of effect of diltiazem in the treatment of Duchennes muscular-dystrophy - a double-blind placebo-controlled study. Wien Klin Wochenschr 1991; 103: 232-235.

115. Satoh H, Ginsburg KS, Qing K, Terada H, Hayashi H, Bers DM. KB-R7943 block of $\mathrm{Ca}(2+)$ influx via $\mathrm{Na}(+) / \mathrm{Ca}(2+)$ exchange does not alter twitches or glycoside inotropy but prevents $\mathrm{Ca}(2+)$ overload in rat ventricular myocytes. Circulation 2000; 101 : 1441-1446.

116. Matsuda T, Arakawa N, Takuma K, Kishida Y, Kawasaki Y, Sakaue M et al. SEA0400, a novel and selective inhibitor of the $\mathrm{Na}+\mathrm{Ca} 2+$ exchanger, attenuates reperfusion injury in 
the in vitro and in vivo cerebral ischemic models. J Pharmacol Exp Ther 2001; 298: 249-256.

117. Cornea RL, Gruber SJ, Lockamy EL, Muretta JM, Jin DZ, Chen JQ et al. High-throughput FRET assay yields allosteric SERCA activators. J Biomol Screen 2013; 18: 97-107.

118. Xu SZ, Beech DJ. TrpC1 is a membrane-spanning subunit of store-operated $\mathrm{Ca} 2+$ channels in native vascular smooth muscle cells. Circ Res 2001; 88: 84-87.

119. Beauge $L$, DiPolo R. SEA-0400, a potent inhibitor of the $\mathrm{Na}+/ \mathrm{Ca} 2+$ exchanger, as a tool to study exchanger ionic and metabolic regulation. Am J Physiol Cell Physiol 2005; 288: C1374-C1380.

120. Urban N, Hill K, Wang LM, Kuebler WM, Schaefer M. Novel pharmacological TRPC inhibitors block hypoxia-induced vasoconstriction. Cell Calcium 2012; 51: 194-206.

121. Kraft $\mathrm{R}$. The $\mathrm{Na}+/ \mathrm{Ca} 2+$ exchange inhibitor KB-R7943 potently blocks TRPC channels. Biochem Biophys Res Commun 2007; 361: 230-236.

122. Kiyonaka S, Kato K, Nishida M, Mio K, Numaga T, Sawaguchi $Y$ et al. Selective and direct inhibition of TRPC3 channels underlies biological activities of a pyrazole compound. Proc Natl Acad Sci USA 2009; 106: 5400-5405.
123. Harguindey S, Arranz JL, Polo Orozco JD, Rauch C, Fais S, Cardone RA et al. Cariporide and other new and powerful NHE1 inhibitors as potentially selective anticancer drugs-an integral molecular/biochemical/metabolic/clinical approach after one hundred years of cancer research. J Trans Med 2013; 11: 282.

(c) (i) ()$\odot$ This work is licensed under a Creative Commons Attribution-NonCommercial-NoDerivs 4.0 International License. The images or other third party material in this article are included in the article's Creative Commons license, unless indicated otherwise in the credit line; if the material is not included under the Creative Commons license, users will need to obtain permission from the license holder to reproduce the material. To view a copy of this license, visit http://creativecommons.org/licenses/by-nc-nd/4.0/ 